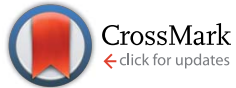

Cite this: Chem. Sci., 2015, 6, 3565

Received 10th March 2015 Accepted 16th April 2015

DOI: $10.1039 /$ c5sc00871a

www.rsc.org/chemicalscience

\section{Can acyclic conformational control be achieved via a sulfur-fluorine gauche effect? $\dagger$}

\begin{abstract}
C. Thiehoff, ${ }^{a}$ M. C. Holland, ${ }^{a b}$ C. Daniliuc, $\star^{a}$ K. N. Houk ${ }^{\star b}$ and R. Gilmour ${ }^{\star a c}$
The gauche conformation of the 1,2-difluoroethane motif is known to involve stabilising hyperconjugative interactions between donor (bonding, $\sigma_{\mathrm{C}-\mathrm{H}}$ ) and acceptor (antibonding, $\sigma_{\mathrm{C}-\mathrm{F}}^{*}$ ) orbitals. This model rationalises the generic conformational preference of $\mathrm{F}-\mathrm{C}_{\beta}-\mathrm{C}_{\alpha}-\mathrm{X}$ systems $\left(\phi_{\mathrm{FCCX}} \approx 60^{\circ}\right)$, where $\mathrm{X}$ is an electron deficient substituent containing a Period 2 atom. Little is known about the corresponding Period 3 systems, such as sulfur and phosphorus, where multiple oxidation states are possible. Conformational analyses of $\beta$-fluorosulfides, -sulfoxides and -sulfones are disclosed here, thus extending the scope of the fluorine gauche effect to the 3rd Period $\left(\mathrm{F}-\mathrm{C}-\mathrm{C}-\mathrm{S}(\mathrm{O})_{n} ; \phi_{\mathrm{FCCS}} \approx 60^{\circ}\right.$ ). Synergy between experiment and computation has revealed that the gauche effect is only pronounced in structures bearing an electropositive vicinal sulfur atom $\left(\mathrm{S}^{+}-\mathrm{O}^{-}, \mathrm{SO}_{2}\right)$.
\end{abstract}

Controlling rotation about $\mathrm{C}\left(\mathrm{sp}^{3}\right)-\mathrm{C}\left(\mathrm{sp}^{3}\right)$ bonds is strategically important in molecular design, not least to determine the spatial positioning of substituents on the component atoms. ${ }^{1}$ Of the various acyclic conformational control strategies in common practice, the fluorine gauche effect $^{2}$ has gained momentum in recent years on account of the minimal steric footprint imposed by this substituent; this often leads to conformer populations that are inaccessible by traditional steric locking approaches. The counterintuitive preference of the parent 1,2-difluoroethane scaffold to populate the gauche conformer preferentially can be rationalised by invoking hyperconjugative $\sigma_{\mathrm{C}-\mathrm{H}} \rightarrow \sigma_{\mathrm{C}-\mathrm{F}}^{*}$ interactions. This conformational preference is conserved in a number of $\mathrm{F}-\mathrm{C}-\mathrm{C}-\mathrm{X}$ systems where $\mathrm{X}$ is electron deficient (Fig. 1). ${ }^{3} \mathrm{~A}$ simplified donor-acceptor model is didactically valuable in rationalising and predicting conformation, while more detailed analysis reveals that both orbital and electrostatic effects are involved. ${ }^{4}$ This is particularly true when $\mathrm{X}$ carries a (partial) positive charge, and electrostatic interactions contribute significantly. The strategic installation of the $\mathrm{F}-\mathrm{C}-\mathrm{C}-\mathrm{X}$ motif can lead to predictable molecular topologies on account of the gauche

${ }^{a}$ Organisch Chemisches Institut, and Excellence Cluster EXC 1003, Cells in Motion, Westfälische Wilhelms-Universität Münster, Corrensstrasse 40, Münster, Germany. E-mail: ryan.gilmour@uni-muenster.de

${ }^{b}$ Department of Chemistry and Biochemistry, University of California Los Angeles, 607 Charles E. Young Drive East, Los Angeles 90095-1569, USA. E-mail: houk@chem.ucla. $e d u$

${ }^{c}$ Excellence Cluster EXC 1003, Cells in Motion, Westfälische Wilhelms-Universität Münster, Münster, Germany

$\dagger$ Electronic supplementary information (ESI) available. CCDC 1048074-1048078. For ESI and crystallographic data in CIF or other electronic format see DOI: 10.1039/c5sc00871a

‡ X-ray crystallographer. effect $\left(\phi_{\mathrm{FCCX}} \approx 60^{\circ}\right)$ : the caveat that stereoelectronic effects can be overridden by prevailing steric factors must always be considered.

This approach to molecular design has found widespread application in catalysis, ${ }^{5}$ bioactive molecule design, ${ }^{6}$ material science $^{7}$ and agrochemistry. ${ }^{8}$ In the majority of cases, the substituent (X) is a Period 2 atom, typically oxygen or nitrogen. In contrast, the manifestation of this phenomenon in combination with 3rd row elements has been largely ignored despite the importance of sulfur and phosphorus containing compounds in industry and academia. Recent interest in the

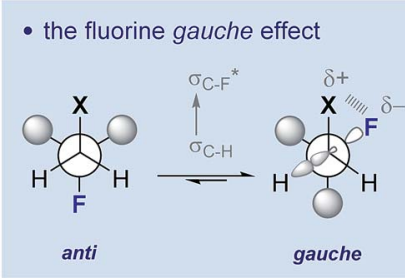

- Period 2 (known)

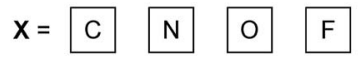

- Period 3 (this work)

$$
\mathrm{X}=\mathrm{S}
$$

- bioactive molecules containing the F-C-C-S motif
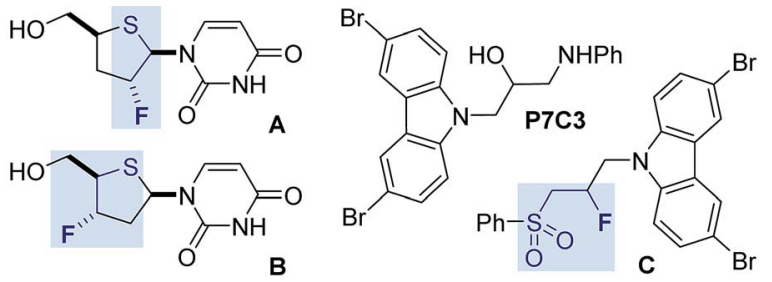

Fig. 1 The fluorine gauche effect. Selected literature precedence for a potential sulfur-fluorine gauche effect. Lower left: fluorinated deoxy$4^{\prime}$-thio pyrimidine nucleosides $\mathrm{A}$ and $\mathrm{B} .{ }^{11}$ Lower right: proneurogenic compound P7C3 and its $\beta$-fluorinated sulfone derivative (C). ${ }^{12}$ 


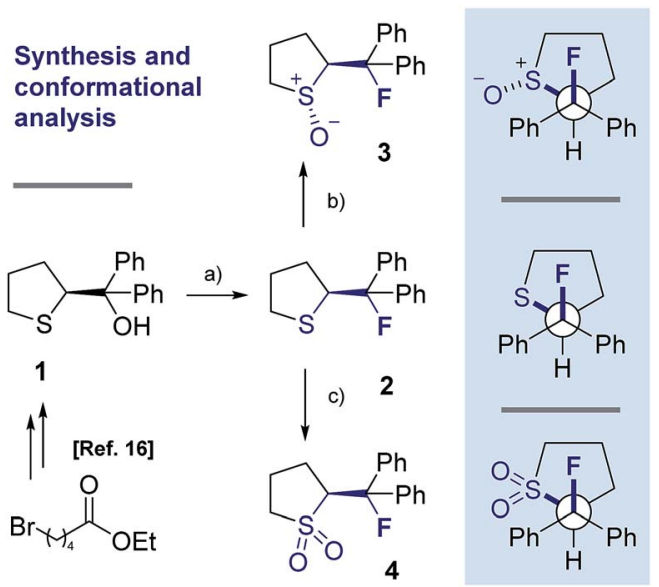

Scheme 1 Synthetic route to the cyclic sulfide 2, sulfoxide 3 and sulfone 4 from 1. (a) DAST, $\mathrm{Na}_{2} \mathrm{CO}_{3}, \mathrm{CH}_{2} \mathrm{Cl}_{2}, 0^{\circ} \mathrm{C}$ to rt, $16 \mathrm{~h}$; (b) $\mathrm{mCPBA}$ (1.0 eq.), $\mathrm{CH}_{2} \mathrm{Cl}_{2}, 0^{\circ} \mathrm{C}$ to rt, $50 \mathrm{~h}$; (c) $m \mathrm{CPBA}$ (3.0 eq.), $\mathrm{CH}_{2} \mathrm{Cl}_{2}, 0^{\circ} \mathrm{C}$ to $\mathrm{rt}, 17 \mathrm{~h}$.

preparation $^{9}$ and properties of compounds containing the $\mathrm{F}-\mathrm{C}-\mathrm{C}-\mathrm{S}(\mathrm{O})_{n}(n=0,1$ and 2$)$ unit prompted this study.

There is limited structural evidence consistent with the postulated sulfur-fluorine gauche effect. In the mid-1980s, Carretero and co-workers reported a NMR study of $\beta$-fluorinated thioethane derivatives, including various sulfides, sulfoxides, sulfones and sulfonium salts. ${ }^{\mathbf{1 0}}$ Vicinal coupling constant analysis is consistent with a gauche orientation of the sulfur and fluorine atoms. Further evidence of this phenomenon derives from the X-ray structure analyses of fluorinated deoxy-4'-thiopyrimidine nucleosides such as $\mathbf{A}$ and $\mathbf{B}$ (Fig. 1), where torsional angles of $\phi_{\mathrm{FCCS}} \approx 80^{\circ}$ approach the expected stereoelectronic requirements despite the constraints imposed by the ring. ${ }^{11}$ Finally, a recent study by Ready and co-workers identified carbazole P7C3 as displaying potent neuroprotective activity. ${ }^{\mathbf{1 2}}$ A lead structure in this investigation is derivative $\mathbf{C}$, containing the $\beta$-fluorosulfone unit. Herein we report a combined experimental and computational study of the fluorine-sulfur gauche effect with specific emphasis on sulfides, sulfoxides and sulfones.

Our recent interest in the fluorine gauche effect in pyrrolidine organocatalysts $(\mathrm{X}=\mathrm{N})^{5 \boldsymbol{a}, \boldsymbol{b}, \boldsymbol{f}}$ led us to explore tetrahydrothiophene derivatives 2, 3 and $\mathbf{4}$ (Scheme 1) as scaffolds for this study. It was envisaged that the diffuse nature of sulfur orbitals, and the polarised nature of the oxidised forms (e.g., $\mathrm{S}^{+}-\mathrm{O}^{-}, \mathrm{SO}_{2}$ ) would generate hyperconjugative and/or chargedipole interactions that might manifest themselves in diagnostic conformations. The heterocycles can exist as synclinalendo and synclinal-exo conformers that can easily be distinguished by vicinal $\left({ }^{3} J\right)$ coupling constant analysis. Structures 2, 3 and 4 were prepared from the intermediate 1 (Scheme 1). ${ }^{13}$ Direct deoxyfluorination of 1 was facile and furnished 2 in 54\% yield. This is noteworthy given the dearth of information of fluorination of this substrate class. Subsequent oxidation to the corresponding sulfoxide 3 proceeded smoothly in 68\% yield and with excellent levels of diastereoselectivity ( $97: 3)$, giving a first insight into the possible role of fluorine in influencing the conformation of such systems. Finally, upon exposure to excess $m \mathrm{CPBA}$, the sulfone 4 was generated in $85 \%$ yield.

\section{X-ray crystal structure analysis}

Single crystals suitable for X-ray analysis were obtained in all cases (Fig. 2). ${ }^{\mathbf{1 4}}$ Each structure exhibited a gauche preference, favouring the synclincal-endo conformation $\left(2,3,4, \phi_{\mathrm{FCCS}}=\right.$ $-62.07^{\circ},-60.89^{\circ},-62.37^{\circ}$, respectively; Table 1). Common to all structures is an unusually long S1-C4 bond length as compared to the $\mathrm{S} 1-\mathrm{C} 1$ bond length (Table $1, \Delta d \approx 0.027 \AA$, $0.039 \AA$, $0.053 \AA$, for 2,3 and 4, respectively). To place this observation in context with comparable sulfur containing structures, a selection of $\mathrm{C}-\mathrm{S}$ bond lengths are provided in Table 1 (right column). ${ }^{15}$ This may be noteworthy in view of the importance of fractional bonds in translating small changes in ground state structures to reactivity. ${ }^{16}$ Importantly, the vicinal $\mathrm{C}-\mathrm{H}$ and $\mathrm{C}-\mathrm{F}$ bonds are antiperiplanar $\left(179^{\circ},-177^{\circ}, 178.15^{\circ}\right)$ thus allowing for stabilising hyperconjugative interactions $\left(\sigma_{\mathrm{C}-\mathrm{H}} \rightarrow \sigma_{\mathrm{C}-\mathrm{F}}^{*}\right)$, with $\mathrm{C}-\mathrm{F}$ bond lengths of $1.41 \AA, 1.42 \AA$ and $1.42 \AA$, for 2,3 and 4 respectively. The solid state structure of sulfoxide 3, prepared by diastereoselective oxidation, reveals a conformation in which the $\mathrm{C}-\mathrm{F}$ and $\mathrm{S}-\mathrm{O}$ dipoles are minimised.

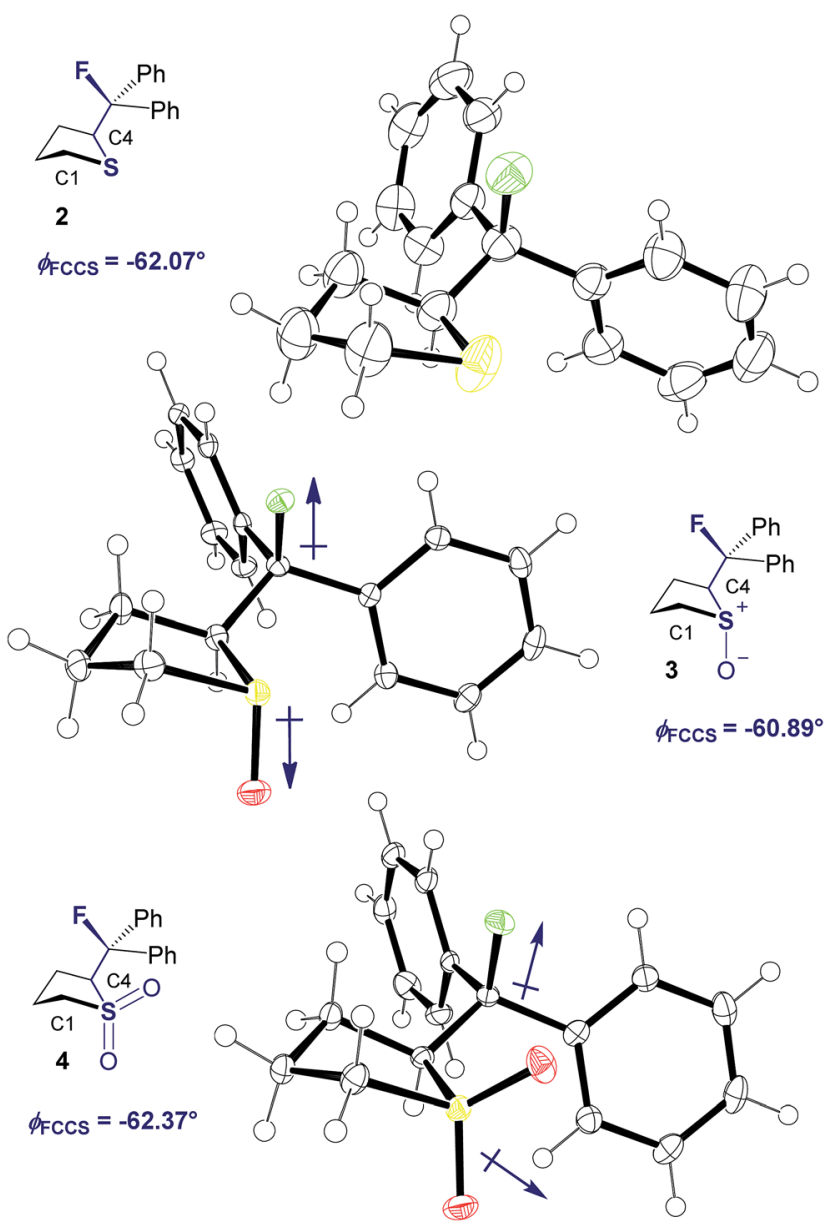

Fig. 2 X-ray structural analyses of cyclic compounds 2, 3 and 4. Thermal ellipsoids shown at 50\% probability level. ${ }^{14}$ 
Table 1 Selected crystallographic data for compounds 2, 3, 4, 6 and 7 (ref. 14)

\begin{tabular}{llllll}
\hline Compound & $\phi_{\mathrm{FCCS}}\left[{ }^{\circ}\right]$ & $d_{\mathrm{S} 1-\mathrm{C} 4}[\AA]$ & $d_{\mathrm{S} 1-\mathrm{C} 1[\AA}[\AA$ & $\Delta d[\AA]$ & Literature $_{\mathrm{S}-\mathrm{C}}[\AA]^{15}$ \\
\hline 2 & -62.07 & $1.8379(16)$ & $1.8107(19)$ & 0.027 & 0.039 \\
3 & -60.89 & $1.853(2)$ & $1.814(2)$ & 0.054 & $1.827^{a}$ \\
$\mathbf{4}$ & -62.37 & $1.832(2)$ & $1.799(2)$ & 0.035 & $1.788^{c}$ \\
7 & -55.87 & $1.764(9)^{d}$ & $1.799(6)^{e}$ & $1.790^{f} / 1.818^{b}$ \\
7 & -68.12 & $1.7789(15)^{d}$ & $1.7791(15)^{e}$ & 0.0002 & $1.763^{g} / 1.786^{c}$
\end{tabular}

${ }^{a}$ In tetrahydrothiophene. ${ }^{b}$ In a $\mathrm{C}-\mathrm{S}(\mathrm{O})-\mathrm{C}$ motif. ${ }^{c}$ In a $\mathrm{C}-\mathrm{S}\left(\mathrm{O}_{2}\right)-\mathrm{C}$ motif. ${ }^{d} \mathrm{~S}-\mathrm{C}\left(\mathrm{sp}^{3}\right)$ bond. ${ }^{e} \mathrm{~S}-\mathrm{C}(\mathrm{Ar})$ bond. ${ }^{f}$ In $\mathrm{C}_{\mathrm{Ar}}-\mathrm{S}(\mathrm{O})-\mathrm{C}$ motif. ${ }^{g}$ In $\mathrm{C}_{\mathrm{Ar}}-\mathrm{S}\left(\mathrm{O}_{2}\right)-\mathrm{C}$ motif.

The sulfone derivative $\mathbf{4}$ preferentially adopts the conformation placing the fluorine atom synclinal-endo to the sulfur centre: this minimises repulsion with the non-bonding electron pairs of the oxygen atoms.

To ensure that the gauche orientation observed in the tetrahydrothiophene derivatives $\mathbf{2}, \mathbf{3}$ and $\mathbf{4}$ is not a consequence of unfavourable non-bonding interactions with the ring, a sterically less demanding, linear system was synthesised for comparison. Reaction of 4-nitrothiophenol with tosylated 2 -fluoroethanol ${ }^{17}$ afforded the linear sulfide 5 ; this was subsequently converted to sulfoxide 6 and sulfone 7 (Scheme 2). It was possible to grow crystals of compounds 6 and 7 that were suitable for X-ray analysis. ${ }^{14}$ In both cases, the C-S and C-F bonds were oriented in the expected gauche arrangement ( 6 and $7, \phi_{\mathrm{FCCS}}=-55.87^{\circ},-68.12^{\circ}$, respectively; Table 1). These conformations allow for $\sigma_{\mathrm{C}-\mathrm{H}} \rightarrow \sigma_{\mathrm{C}-\mathrm{F}}^{*}$ interactions, again indicating that this effect likely is due in part to hyperconjugative stabilisation. Consistent with structure 3 (Fig. 2, centre), the
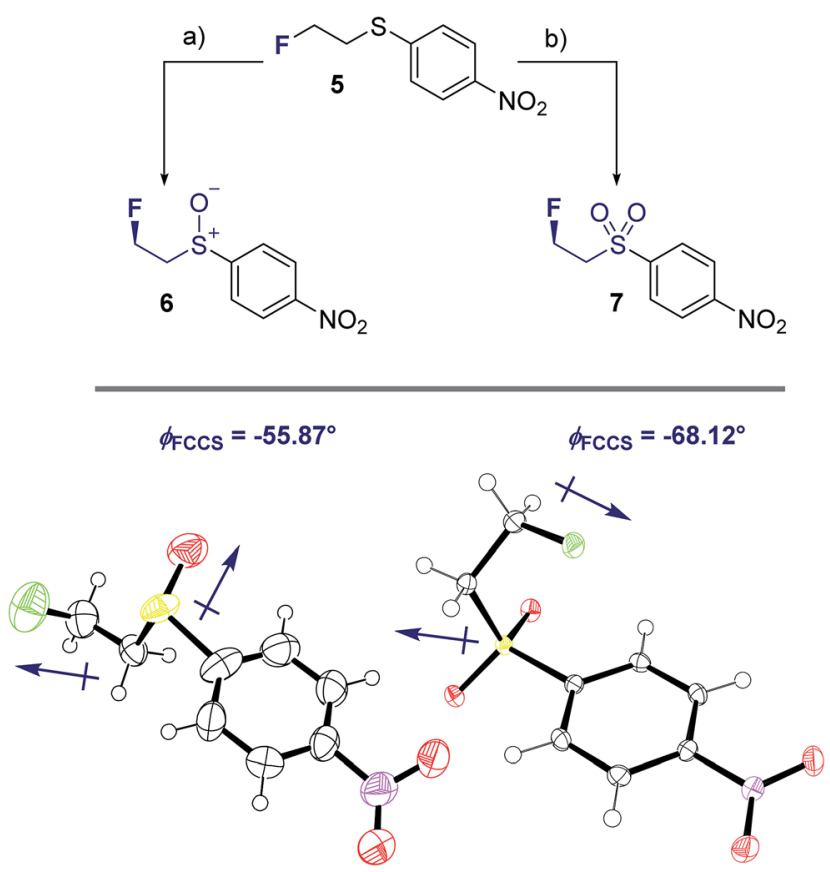

Scheme 2 Syntheses and X-ray crystal structure analyses ${ }^{14}$ of linear sulfoxide 6 and sulfone 7. (a) $m \mathrm{CPBA}\left(1.0\right.$ eq.), $\mathrm{CH}_{2} \mathrm{Cl}_{2}, 0{ }^{\circ} \mathrm{C}$ to rt, $26 \mathrm{~h}$; (b) $m \mathrm{CPBA}$ (3.0 eq.), $\mathrm{CH}_{2} \mathrm{Cl}_{2}, \mathrm{O}^{\circ} \mathrm{C}$ to $\mathrm{rt}, 17 \mathrm{~h}$. Thermal ellipsoids shown at $50 \%$ probability level.
X-ray analysis of sulfoxide 6 reveals a conformation where the $\mathrm{C}-\mathrm{F}$ and $\mathrm{S}-\mathrm{O}$ dipoles oppose each other. In sulfone 7, the C-F bond adopts a gauche arrangement that circumvents interaction with the $\mathrm{SO}_{2}$ unit.

\section{NMR solution phase conformational analysis}

To complement the solid state investigation, a solution phase NMR conformer population analysis of the cyclic compounds was performed. ${ }^{18}$ Assuming that only staggered conformers with torsion angles of $-60^{\circ}$ (-gauche), $60^{\circ}($ gauche $)$ and $180^{\circ}$ (anti) contribute significantly to the population in solution phase, the measured coupling constant $\langle J\rangle$ can be described by the equation $\langle J\rangle=x_{-g} J_{-g}+x_{+g} J_{+g}+x_{a} J_{\mathrm{a}}$. Furthermore, the approximation that the dependency of $J$ is symmetrical about $0^{\circ}$ (ref. 19) renders the following simplification valid: $J_{-g}=J_{+g}=$ $J_{\mathrm{g}}$. Hence, the molar fraction of the anti conformer can be determined according to the following expression: $x_{\mathrm{a}}=(\langle J\rangle-$ $\left.J_{\mathrm{g}}\right) /\left(J_{\mathrm{a}}-J_{\mathrm{g}}\right){ }^{20}$ Whilst literature values for ${ }^{3} J_{\mathrm{CF}}$ are available $\left(J_{\mathrm{g}}=1.2 \mathrm{~Hz}, J_{\mathrm{a}}=11.2 \mathrm{~Hz}\right)^{21}$ the related ${ }^{3} J_{\mathrm{HF}}$ can be calculated based on a modified Karplus equation..$^{22}$ Inserting the measured ${ }^{3} J$ coupling constants (Table 2) allows for the determination of combined populations of the -gauche and +gauche conformers of $>80 \%$ in all cases. Comparison of the ${ }^{3} J_{\mathrm{HF}}$

Table 2 Conformational analysis of cyclic sulfur systems 2, 3 and 4 in solution phase based on ${ }^{3} \mathrm{~J}$ coupling constant analysis

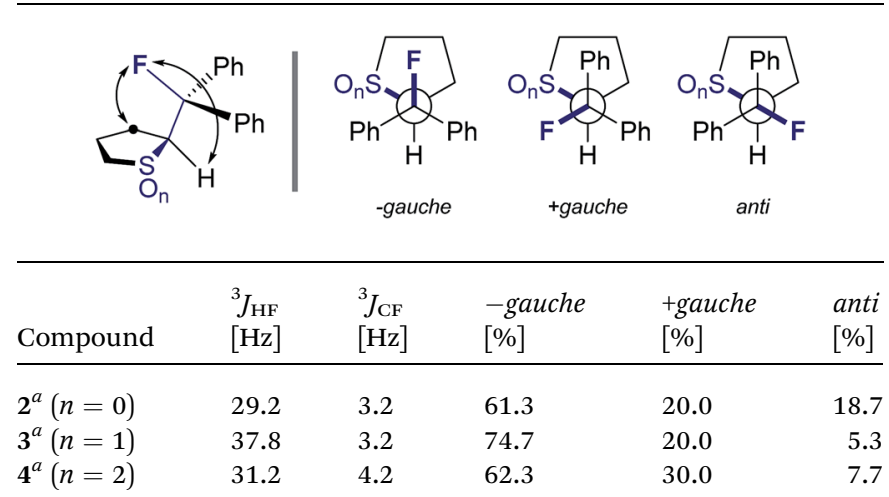

${ }^{a}$ Group electronegativity values for calculation ${ }^{22}$ of ${ }^{3} J_{\mathrm{HF}}$ were taken from the literature ${ }^{23}$ (2: 0.76 [SH group] and 3/4: 0.69 [ $\mathrm{SO}_{2} \mathrm{Cl}$ group]). 
coupling constants of both series reveals the following trend: upon oxidation of the sulfide to the corresponding sulfoxide, a significant increase in the magnitude of the coupling constant is observed $\left({ }^{3} J_{\mathrm{HF}}=29.2,37.8\right.$ and $19.2,30.0 \mathrm{~Hz}$ for 2,3 and 5, 6, respectively). Further oxidation to the sulfone results in coupling constant values that are only slightly augmented relative to those of the parent sulfides $\left({ }^{3} J_{\mathrm{HF}}=31.2\right.$ and $23.8 \mathrm{~Hz}$ for 4 and 7, respectively). These analyses reveal that the major solution phase conformers closely resemble the solid state structures determined by crystallography, and are fully consistent with the notion of a sulfur-fluorine gauche effect.

\section{DFT conformational analysis}

In order to quantify the observed conformational preferences using DFT, a series of structures containing the key F-C-C-S(O) $)_{n}$ unit ( $n=0,1$ and 2 ) were optimised at the $\mathrm{B}^{2} \mathrm{LYP}^{24} / 6-311+\mathrm{G}(\mathrm{d}, \mathrm{p})^{25}$ level of theory. Solvation by dichloromethane was taken into account using the integral equation formalism polarizable continuum model (IEFPCM). ${ }^{26}$ Dichloromethane was chosen to ensure consistency with the NMR solution phase conformational analysis. The choice of basis set was

Table 3 Calculated relative conformational energies and torsion angle of 1,2-difluoroethane (8), (2-fluoroethyl)(methyl)-sulfide (9), -sulfoxide (10), and -sulfone (11). Results obtained with B3LYP/6-311+G(d,p)/ IEFPCM. Only the gauche conformer is shown for simplicity

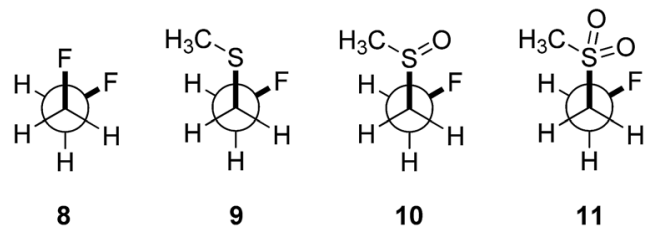

\begin{tabular}{|c|c|c|c|c|c|c|}
\hline & $\phi_{\mathrm{CSCC}}$ & $\phi_{\mathrm{FCC}(\mathrm{F} / \mathrm{S})}$ & $\begin{array}{l}\Delta G \\
{\left[\mathrm{kcal} \mathrm{mol}^{-1}\right]}\end{array}$ & $\begin{array}{l}\phi_{\mathrm{FCC}(\mathrm{F} / \mathrm{S})} \\
{\left[^{\circ}\right]}\end{array}$ & $Q_{\mathrm{S}}{ }^{a}$ & $\begin{array}{l}\mu^{b} \\
{[\mathrm{D}]}\end{array}$ \\
\hline \multirow[t]{2}{*}{8} & - & -gauche & 0.0 & 69 & - & 3.71 \\
\hline & - & anti & 1.9 & 180 & - & 0.00 \\
\hline \multirow[t]{5}{*}{9} & anti & -gauche & 1.0 & -66 & 0.01 & 4.11 \\
\hline & anti & anti & 1.2 & 180 & 0.01 & 2.30 \\
\hline & -gauche & -gauche & 0.7 & 66 & 0.23 & 4.08 \\
\hline & +gauche & anti & 0.0 & -179 & 0.23 & 2.20 \\
\hline & +gauche & -gauche & 0.5 & -68 & 0.21 & 1.89 \\
\hline \multirow[t]{7}{*}{10} & anti & +gauche & 1.8 & 67 & 0.67 & 7.97 \\
\hline & anti & anti & 1.0 & 180 & 0.68 & 5.03 \\
\hline & anti & -gauche & 0.0 & -67 & 0.70 & 5.98 \\
\hline & +gauche & +gauche & 1.4 & 62 & 0.64 & 6.04 \\
\hline & +gauche & anti & 2.1 & 170 & 0.66 & 5.20 \\
\hline & +gauche & -gauche & 0.9 & -70 & 0.66 & 4.44 \\
\hline & -gauche & anti & 1.9 & -166 & 0.65 & 5.38 \\
\hline \multirow[t]{5}{*}{11} & anti & -gauche & 1.2 & -70 & 0.57 & 8.01 \\
\hline & anti & anti & 1.6 & 180.0 & 0.51 & 5.15 \\
\hline & +gauche & -gauche & 0.0 & -70 & 0.45 & 4.91 \\
\hline & -gauche & anti & 1.8 & -178 & 0.42 & 5.26 \\
\hline & -gauche & -gauche & 2.1 & -76 & 0.39 & 7.79 \\
\hline
\end{tabular}

${ }^{a}$ Mulliken atomic charges with hydrogens summed into heavy atoms. ${ }^{b}$ Molecular dipole moment in Debye. based on a previous computational study of the gauche effect in $\alpha$-X- $\beta$-fluoro-ethane derivatives (X $=$ F, NR, OR, CR) by O'Hagan and co-workers. ${ }^{4 c}$ All computations were performed using Gaussian09. ${ }^{27}$ Free energy corrections were calculated using Truhlar's quasi-harmonic approximation. ${ }^{28}$ The lowest energy conformers of 1,2-difluoroethane (8) and the corresponding (2-fluoroethyl)-(methyl)-derivatives (sulfide $=\mathbf{9}$, sulfoxide $=\mathbf{1 0}$, sulfone $=11$ ) were investigated (Table 3). Additionally, the $\mathrm{C}_{\alpha}-\mathrm{C}_{\beta}$ bond rotational profiles (step size $=5^{\circ}, 72$ steps, B3LYP/6-
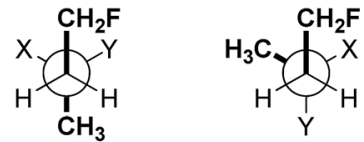

CSCC anti

CScC gauche
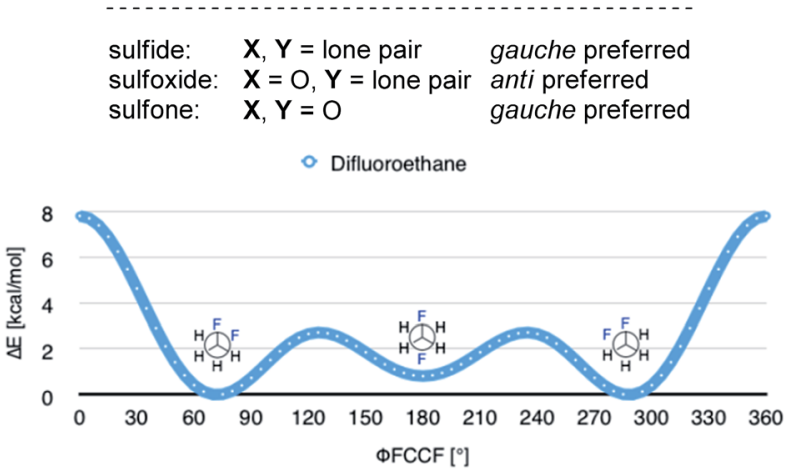

- Ethansulfide ( $\Phi C S C C$ anti) $\circ$ Ethanesulfide ( $\Phi C S C C$ gauche)
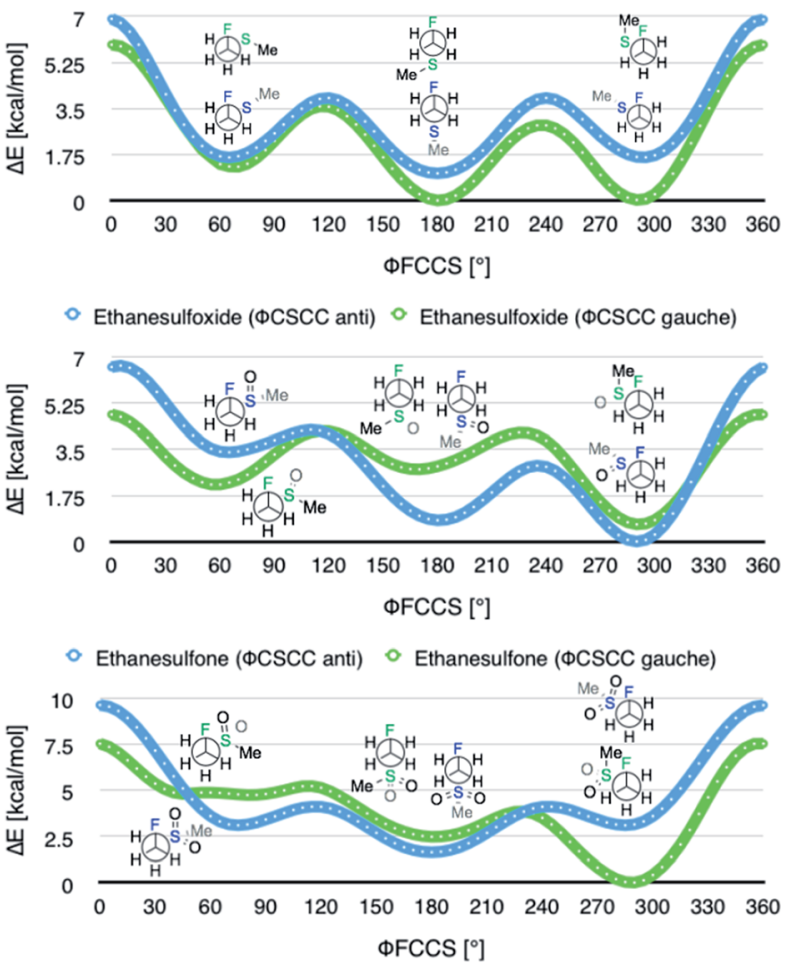

Fig. 3 Conformational preferences around the CSCC bond for 1,2difluoroethane (8), (2-fluoroethyl)(methyl)-sulfide (9), -sulfoxide (10), and -sulfone (11). Results obtained with B3LYP/6-311+G(d,p) in vacuum. 
Table 4 Calculated relative conformational energies and torsion angle of (2-fluoroethyl) (4-nitrophenyl)-sulfide (5), -sulfoxide (6), and -sulfone (7). Results obtained with B3LYP/6-311+G(d,p)/IEFPCM. Only the gauche conformer is shown for simplicity

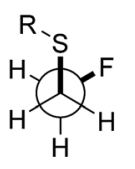

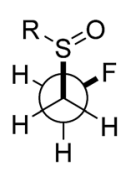

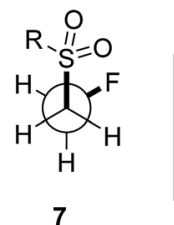

7<smiles>[R]=[N+]([O-])c1ccc([N+](=O)[O-])cc1</smiles>

\begin{tabular}{|c|c|c|c|c|c|c|}
\hline & $\phi_{\mathrm{CSCC}}$ & $\phi_{\text {FCCS }}$ & 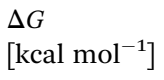 & $\begin{array}{l}\phi_{\mathrm{FCCS}} \\
{\left[^{\circ}\right]}\end{array}$ & $Q_{\mathrm{S}}{ }^{a}$ & $\begin{array}{l}\mu^{b} \\
{[\mathrm{D}]}\end{array}$ \\
\hline \multirow[t]{5}{*}{5} & anti & +gauche & 0.0 & 66 & -0.67 & 7.07 \\
\hline & anti & anti & 0.4 & 180 & -0.65 & 6.20 \\
\hline & +gauche & +gauche & 0.2 & 64 & -0.38 & 6.68 \\
\hline & +gauche & anti & 0.1 & 179 & -0.34 & 6.12 \\
\hline & +gauche/eclipsed & -gauche & 0.1 & -69 & -0.30 & 9.55 \\
\hline \multirow[t]{6}{*}{6} & anti & +gauche & 1.7 & 68 & 0.85 & 6.62 \\
\hline & anti & anti & 1.3 & 180 & 0.95 & 4.32 \\
\hline & anti & -gauche & 0.0 & -66 & 0.89 & 4.65 \\
\hline & +gauche & +gauche & 1.7 & 62 & 1.01 & 4.62 \\
\hline & +gauche & anti & 2.9 & 173 & 1.01 & 4.15 \\
\hline & eclipsed & -gauche & 1.8 & -67 & 0.82 & 6.55 \\
\hline \multirow[t]{5}{*}{7} & anti & -gauche & 0.9 & -70 & 0.63 & 5.74 \\
\hline & anti & anti & 1.3 & -179 & 0.58 & 2.50 \\
\hline & +gauche & -gauche & 0.0 & -72 & 0.66 & 5.85 \\
\hline & +gauche & anti & 1.4 & 179 & 0.63 & 2.55 \\
\hline & +gauche & +gauche & 1.4 & 72 & 0.61 & 5.65 \\
\hline
\end{tabular}

${ }^{a}$ Mulliken atomic charges with hydrogens summed into heavy atoms.

${ }^{b}$ Molecular dipole moment in Debye.

$311+\mathrm{G}(\mathrm{d}, \mathrm{p})$ in vacuum) of $\mathbf{9 - 1 1}$, with both the CSCC anti and gauche conformations, were calculated and compared to the rotational profile of 1,2-difluoroethane (8) (Fig. 3, top).

This analysis confirmed that the well known gauche preference of 1,2-difluoroethane (8) is also inherent to the linear sulfoxide and sulfone derivatives $\left(\Delta G_{\text {anti/gauche }}=1.9,1.0\right.$, and $1.6 \mathrm{kcal} \mathrm{mol}^{-1}$, for $\mathbf{8 , 1 0}$ and $\mathbf{1 1}$ respectively). However, the sulfide derivative $\mathbf{9}$ displays a slight preference for the anti conformation $\left(\Delta G_{\text {gauche/anti }}=0.5 \mathrm{kcal} \mathrm{mol}^{-1}\right)$; this is at variance with the X-ray structures of 2 (Fig. 2). As expected, the gauche conformation appears to be more pronounced in structures bearing a more electropositive vicinal sulfur atom $\left(\mathrm{S}^{+}-\mathrm{O}^{-}, \mathrm{SO}_{2}\right)$.

As a quantitative measurement for this effect, the Mulliken atomic charges $\left(Q_{\mathrm{S}}\right)$ of the sulfur atom in each of the conformers studied were calculated. These are listed in Table 3 (right). Interestingly, comparison of the energy minima in compounds 9-11 displayed some variation with respect to the CSCC chain. Whereas the sulfide $\mathbf{9}$ and the sulfone $\mathbf{1 1}$ position the two alkylgroups gauche to each other in the lowest lying minima, the sulfoxide 10 preferentially orients the groups anti (Fig. 3).

A computational analysis of the linear 4-nitrothiophenol derived systems 5-7 (Table 4) revealed similar trends to those observed with the ethane derivatives (Table 3, also see Scheme 2). The sulfide derivative 5 displayed no significant preference for the gauche or anti conformation $\left(5, \Delta G_{\text {gauchelanti }}=0.1\right.$ kcal $\mathrm{mol}^{-1}$ ), whilst the sulfoxide and sulfone derivatives both exhibited a gauche preference ( 6 and $7, \Delta G_{\text {anti/anti }}=1.3$ and $1.3 \mathrm{kcal} \mathrm{mol}^{-1}$, respectively).

The three possible rotamers of cyclic compounds 2, 3 and 4 were also investigated (Table 5). For the sulfoxide derivative $\mathbf{3}$ both diastereoisomers (oxygen anti 3a, and syn $\mathbf{3 b}$ ) were

Table 5 Calculated relative conformational energies and torsion angle of cyclic sulfide 2, sulfoxide 3, and sulfone 4. Results obtained with B3LYP/6-311+G(d,p)/IEFPCM. Only the gauche conformer is shown for simplicity

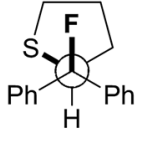

2

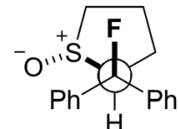

$3 a$

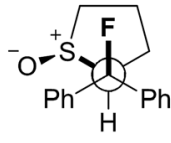

3b

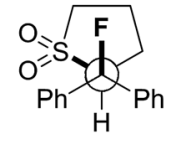

4

\begin{tabular}{|c|c|c|c|c|c|c|}
\hline & $\begin{array}{l}\Delta d_{\mathrm{S} 1-\mathrm{C} 4 / \mathrm{S} 1-\mathrm{C} 1} \\
{[\AA]}\end{array}$ & $\phi_{\text {FCCS }}$ & $\begin{array}{l}\Delta G \\
{\left[\mathrm{kcal} \mathrm{mol}^{-1}\right]}\end{array}$ & $\begin{array}{l}\phi_{\mathrm{FCCS}} \\
{\left[{ }^{\circ}\right]}\end{array}$ & $Q_{\mathrm{S}}{ }^{a}$ & $\begin{array}{l}\mu^{b} \\
{[\mathrm{D}]}\end{array}$ \\
\hline \multirow[t]{3}{*}{2} & 0.021 & +gauche & 3.3 & 64 & 0.07 & 4.92 \\
\hline & 0.018 & anti & 1.7 & -176 & -0.08 & 1.76 \\
\hline & 0.022 & -gauche & 0.0 & -63 & -0.12 & 3.25 \\
\hline \multirow[t]{3}{*}{$3 \mathbf{a}^{c}$} & 0.057 & +gauche & 2.4 & 46 & 0.84 & 8.38 \\
\hline & 0.045 & anti & 2.7 & 172 & 0.84 & 5.51 \\
\hline & 0.050 & -gauche & 0.0 & -63 & 0.81 & 5.09 \\
\hline \multirow[t]{3}{*}{$3 \mathbf{b}^{d}$} & 0.012 & +gauche/eclipsed & 5.7 & 26 & 0.78 & 7.15 \\
\hline & 0.012 & anti & 4.2 & 158 & 0.62 & 3.89 \\
\hline & 0.042 & -gauche & 3.7 & -70 & 0.68 & 7.25 \\
\hline \multirow[t]{3}{*}{4} & 0.039 & +gauche & 3.0 & 34 & 0.71 & 9.12 \\
\hline & 0.034 & anti & 2.9 & 161 & 0.52 & 5.42 \\
\hline & 0.050 & -gauche & 0.0 & -66 & 0.70 & 6.88 \\
\hline
\end{tabular}

${ }^{a}$ Mulliken atomic charges with hydrogens summed into heavy atoms. ${ }^{b}$ Molecular dipole moment in Debye. ${ }^{c}$ Oxygen anti. ${ }^{d}$ Oxygen syn. 


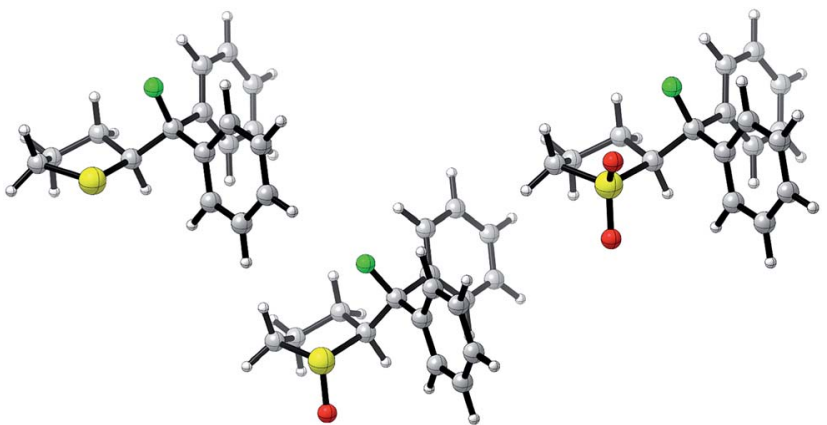

Fig. 4 Global energy minima for cyclic sulfide 2, sulfoxide 3, and sulfone 4, all adopting the experimentally observed synclinal-endo (gauche) conformation. Results obtained with B3LYP/6-311+G(d,p)/ IEFPCM. $\mathrm{S}=$ yellow, $\mathrm{O}=$ red, $\mathrm{F}=$ green .

considered, although only the anti diastereoisomer was isolated following oxidation. In this case, the syn conformer is significantly higher in energy than the anti $\left(\Delta G_{\text {syn/anti }}=3.7 \mathrm{kcal} \mathrm{mol}^{-1}\right)$.

The sulfide (2) again shows the smallest energetic difference between the lowest lying anti and syn conformations, consistent with the results for the acyclic derivatives. Contrary to the other structures investigated, this cyclic derivative exhibits a significant preference for the gauche conformation $\left(\Delta G_{\text {antilgauche }}=1.7\right.$ $\mathrm{kcal} \mathrm{mol}^{-1}$ ). For the derivatives bearing a more electron deficient sulfur atom, the gauche preference is more pronounced ( 3 and $4, \Delta G_{\text {antilgauche }}=2.4$ and $2.9 \mathrm{kcal} \mathrm{mol}^{-1}$, respectively). The synclinal-endo conformation is significantly lower in energy than the synclinal-exo conformation, and the latter is higher in energy than the anti. The optimised structures displayed the same lengthening of the S1-C4 bond as was observed by crystallography. The global energy minima for compounds 2,3 and $\mathbf{4}$ are shown in Fig. 4 and closely match the corresponding X-ray structures (Fig. 2).

\section{Conclusions}

Computation and experiment confirm that the $\mathrm{F}-\mathrm{C}-\mathrm{C}-\mathrm{S}$ motif has an intrinsic gauche conformational preference. Conformational analysis in both solid and solution phase confirmed that the $\mathrm{C}-\mathrm{F}$ bond aligns anti to a vicinal $\mathrm{C}-\mathrm{H}$ bond, reasonably to allow for stabilising hyperconjugative interactions of the type $\sigma_{\mathrm{C}-\mathrm{H}} \rightarrow \sigma_{\mathrm{C}-\mathrm{F}}^{*}$. The $\Delta G_{\text {gauchelanti }}$ value is larger when the sulfur centre is more electron deficient; this is especially pronounced in sulfoxides. Computational analyses indicate that the conformational preference is not solely due to overall molecular dipole minimisation (Table 3,4 and 5, right column). This study extends the well-known gauche effect to $3^{\text {rd }}$ Period substituents, and validates the notion that the $\mathrm{F}-\mathrm{C}-\mathrm{C}-\mathrm{S}(\mathrm{O})_{n}$ unit may be strategically embedded into functional scaffolds to achieve acyclic conformational control.

\section{Acknowledgements}

We acknowledge generous financial support from the WWU Münster, the Deutsche Forschungsgemeinschaft (SFB 858, and
Excellence Cluster EXC 1003 "Cells in Motion - Cluster of Excellence"), the German Academic Exchange Service DAAD (P.R.I.M.E. fellowship M. C. Holland) and the U.S. National Science Foundation (CHE-1361104).

\section{Notes and references}

1 R. W. Hoffmann, Angew. Chem., Int. Ed., 2000, 39, 2054.

2 (a) S. Wolfe, Acc. Chem. Res., 1972, 5, 102; (b) D. O'Hagan, Chem. Soc. Rev., 2008, 37, 308; (c) L. Hunter, Beilstein J. Org. Chem., 2010, (6), No. 38, DOI: 10.3762/bjoc.6.38; (d) L. E. Zimmer, C. Sparr and R. Gilmour, Angew. Chem., Int. Ed., 2011, 50, 11860.

3 For selected examples see: (a) K. S. Buckton and R. G. Azrak, J. Chem. Phys., 1970, 52, 5652; (b) K. Hagen and K. Hedberg, J. Am. Chem. Soc., 1973, 95, 8263; (c) J. Huang and K. Hedberg, J. Am. Chem. Soc., 1989, 111, 6909; (d) D. A. Dixon and B. E. Smart, J. Phys. Chem., 1991, 95, 1609; (e) D. O'Hagan, C. Bilton, J. A. K. Howard, L. Knight and D. J. Tozer, J. Chem. Soc., Perkin Trans. 2, 2000, 605; (f) C. R. S. Briggs, M. J. Allen, D. O'Hagan, D. J. Tozer, A. M. Z. Slawin, A. E. Goeta and J. A. K. Howard, Org. Biomol. Chem., 2004, 2, 732; (g) C. R. S. Briggs, D. O'Hagan, H. S. Rzepa and A. M. Z. Slawin, J. Fluorine Chem., 2004, 125, 19; (h) M. Morgenthaler, E. Schweizer, A. Hoffman-Röder, F. Benini, R. E. Martin, G. Gaeschke, B. Wagner, H. Fischer, S. Bendels, D. Himmerli, J. Schneider, F. Diederich, M. Kansy and K. Müller, ChemMedChem, 2007, 2, 1100; (i) N. E. J. Gooseman, D. O'Hagan, M. J. G. Peach, A. M. Z. Slawin, D. J. Tozer and R. J. Young, Angew. Chem., Int. Ed., 2007, 46, 5904; (j) G. Deniau, A. M. Z. Slawin, T. Lebl, F. Chorki, J. P. Issberner, T. van Mourik, J. M. Heygate, J. J. Lambert, K. T. Sillar and D. O'Hagan, ChemBioChem, 2007, 8, 2265; (k) C. Bucher, C. Sparr, W. B. Schweizer and R. Gilmour, Chem.-Eur. J., 2009, 15, 7637; (l) C. Sparr and R. Gilmour, Angew. Chem., Int. Ed., 2010, 49, 6520; $(m)$ C. Sparr, E.-M. Tanzer, J. Bachmann and R. Gilmour, Synthesis, 2010, 1394; (n) S. Paul, W. B. Schweizer, M.-O. Ebert and R. Gilmour, Organometallics, 2010, 29, 4424; (o) C. Sparr, E. Salamanova, W. B. Schweizer, H. M. Senn and R. Gilmour, Chem.-Eur. J., 2011, 17, 8850; (p) S. Paul, W. B. Schweizer, G. Rugg, H. M. Senn and R. Gilmour, Tetrahedron, 2013, 69, 4647.

4 (a) L. Goodman, H. Gu and V. Pophristic, J. Phys. Chem. A, 2005, 109, 1223; (b) P. R. Rablen, R. W. Hoffmann, D. A. Hrovat and W. T. Borden, J. Chem. Soc., Perkin Trans. 2, 1999, 1719; (c) D. Y. Buissonnneaud, T. van Mourik and D. O'Hagan, Tetrahedron, 2010, 66, 2196; (d) M. BaranacStojanović, $R S C A d v$., 2014, 4, 43834; (e) For a recent study of the gauche effect in 2,3-difluorobutane see S. J. Fox, S. Gourdain, A. Coulthurst, C. Fox, I. Kuprov, J. W. Essex, C. K. Skylaris and B. Linclau, Chem.-Eur. J., 2015, 21, 1682.

5 (a) C. Sparr, W. B. Schweizer, H. M. Senn and R. Gilmour, Angew. Chem., Int. Ed., 2009, 121, 3111; (b) E.-M. Tanzer, L. E. Zimmer, W. B. Schweizer and R. Gilmour, Chem.-Eur. J., 2012, 18, 11334; (c) E.-M. Tanzer, W. B. Schweizer, 
M.-O. Ebert and R. Gilmour, Chem.-Eur. J., 2012, 18, 2006; (d) Y. P. Rey and R. Gilmour, Beilstein J. Org. Chem., 2013, 9, 2812; (e) Y. P. Rey, L. E. Zimmer, C. Sparr, E.-M. Tanzer, W. B. Schweizer, H. M. Senn, S. Lakhdar and R. Gilmour, Eur. J. Org. Chem., 2014, 1202; $(f)$ I. G. Molnár, E.-M. Tanzer, C. Daniliuc and R. Gilmour, Chem.-Eur. J., 2014, 20, 794.

6 (a) D. O'Hagan and H. S. Rzepa, Chem. Commun., 1997, 645; (b) M. L. DeRider, S. J. Wilkens, M. J. Waddell, L. E. Bretscher, F. Weinhold, R. T. Raines and J. L. Markley, J. Am. Chem. Soc., 2002, 124, 2497; (c) For an excellent review see: S. Purser, P. R. Moore, S. Swallow and V. Gouverneur, Chem. Soc. Rev., 2008, 37, 320.

7 (a) L. Hunter and D. O'Hagan, Org. Biomol. Chem., 2008, 6, 2843; (b) D. Farran, A. M. Z. Slawin, P. Kirsch and D. O'Hagan, J. Org. Chem., 2009, 74, 7168; (c) L. Hunter, P. Kirsch, A. M. Z. Slawin and D. O'Hagan, Angew. Chem., Int. Ed., 2009, 48, 5457; (d) P. Kirsch, A. Hahn, R. Fröhlich and G. Haufe, Eur. J. Org. Chem., 2006, 4819; (e) M. Nicoletti, M. Bremer, P. Kirsch and D. O'Hagan, Chem. Commun., 2007, 5075.

8 D. Stierli, J. J. Taylor, H. Walter, P. A. Worthington and R. Rajan, Preparation of $N$-(1-alkyl-2-phenylethyl)azole carboxamides as agrochemical fungicides, PCT Int. Appl. 2007, WO 2007141009 A1 20071213, 2007.

9 For a recent example see: Z. Yuan, H.-Y. Wang, X. Mu, P. Chen, Y.-L. Guo and G. Liu, J. Am. Chem. Soc., 2015, 137, 2468.

10 (a) J. C. Carretero, J. L. Garcia Ruano, M. C. Martinez and J. H. Rodriguez, Tetrahedron, 1985, 41, 2419; (b) J. C. Carretero, J. L. Garcia Ruano, M. C. Martinez and J. H. Rodriguez, An. Quim., Ser. C, 1987, 83, 300.

11 (a) L. S. Jeong, M. C. Nicklaus, C. George and V. E. Marquez, Tetrahedron Lett., 1994, 35, 7569; (b) L. S. Jeong, M. C. Nicklaus, C. George and V. E. Marquez, Tetrahedron Lett., 1994, 35, 7573.

12 (a) K. S. MacMillan, J. Naidoo, J. Liang, L. Melito, N. S. Williams, L. Morlock, P. J. Huntington, S. J. Estill, J. Longgood, G. L. Becker, S. L. McKnight, A. A. Pieper, J. K. De Brabander and J. M. Ready, J. Am. Chem. Soc., 2011, 133, 1428; (b) J. Naidoo, H. De Jesus-Cortes, P. Huntington, S. Estill, L. K. Morlock, R. Starwalt, T. J. Mangano, N. S. Williams, A. A. Pieper and J. M. Ready, J. Med. Chem., 2014, 57, 3746; (c) For a review see: A. A. Pieper, S. L. McKnight and J. M. Ready, Chem. Soc. Rev., 2014, 43, 6716 and references cited therein.

13 H.-Y. Wu, C.-W. Chang and R.-J. Chein, J. Org. Chem., 2013, 78, 5788 .

14 ESI. $\dagger$

15 For bond lengths of organic compounds determined by X-ray and neutron diffraction see: F. H. Allen, O. Kennard,
D. G. Watson, L. Brammer, A. G. Orpen and R. Taylor, J. Chem. Soc., Perkin Trans. 2, 1987, S1-S19.

16 H.-B. Bürgi and J. D. Dunitz, J. Am. Chem. Soc., 1987, 109, 2924.

17 D. Asanuma, Y. Takaoka, S. Namiki, K. Takikawa, M. Kamiya, T. Nagano, Y. Urano and K. Hirose, Angew. Chem., Int. Ed., 2014, 53, 6085.

18 W. B. Dolbier Jr, Guide to Fluorine NMR for Organic Chemists, Wiley, 2009.

19 R. Contreras and J. Peralta, Prog. Nucl. Magn. Reson. Spectrosc., 2000, 37, 321.

20 K. Pachler, Spectrochim. Acta, 1964, 20, 581.

21 A. Dahbi, S. Hamman and C. G. Béguin, Magn. Reson. Chem., 1986, 24, 337.

22 C. Thibaudeau, J. Plavec and J. Chattopadhyaya, J. Org. Chem., 1998, 63, 4967.

23 C. Altona, J. H. Ippel, A. J. A. Westra Hoekzema, C. Erkelens, M. Groesbeek and L. A. Donders, Magn. Reson. Chem., 1989, 27,564 .

24 (a) S. H. Vosko, L. Wilk and M. Nusair, Can. J. Phys., 1980, 58, 1200; (b) C. Lee, W. Yang and R. G. Parr, Phys. Rev. B: Condens. Matter Mater. Phys., 1988, 37, 785; (c) A. D. Becke, J. Chem. Phys., 1993, 98, 5648; (d) P. J. Stephens, F. J. Devlin, C. F. Chabalowski and M. J. Frisch, J. Phys. Chem., 1994, 98, 11623.

25 E. R. Davidson and D. Feller, Chem. Rev., 1986, 86, 681.

26 E. Cancès, B. Mennucci and J. Tomasi, J. Chem. Phys., 1997, 107, 3032.

27 M. J. Frisch, G. W. Trucks, H. B. Schlegel, G. E. Scuseria, M. A. Robb, J. R. Cheeseman, G. Scalmani, V. Barone, B. Mennucci, G. A. Petersson, H. Nakatsuji, M. Caricato, X. Li, H. P. Hratchian, A. F. Izmaylov, J. Bloino, G. Zheng, J. L. Sonnenberg, M. Hada, M. Ehara, K. Toyota, R. Fukuda, J. Hasegawa, M. Ishida, T. Nakajima, Y. Honda, O. Kitao, H. Nakai, T. Vreven, J. A. Montgomery Jr, J. E. Peralta, F. Ogliaro, M. Bearpark, J. J. Heyd, E. Brothers, K. N. Kudin, V. N. Staroverov, T. Keith, R. Kobayashi, J. Normand, K. Raghavachari, A. Rendell, J. C. Burant, S. S. Iyengar, J. Tomasi, M. Cossi, N. Rega, J. M. Millam, M. Klene, J. E. Knox, J. B. Cross, V. Bakken, C. Adamo, J. Jaramillo, R. Gomperts, R. E. Stratmann, O. Yazyev, A. J. Austin, R. Cammi, C. Pomelli, J. W. Ochterski, R. L. Martin, K. Morokuma, V. G. Zakrzewski, G. A. Voth, P. Salvador, J. J. Dannenberg, S. Dapprich, A. D. Daniels, Ö. Farkas, J. B. Foresman, J. V. Ortiz, J. Cioslowski and D. J. Fox, Gaussian 09, revision D.01, Gaussian, Inc., Wallingford, CT, 2013.

28 (a) R. F. Ribeiro, A. V. Marenich, C. J. Cramer and D. G. Truhlar, J. Phys. Chem. B, 2011, 115, 14556; (b) Y. Zhao and D. G. Truhlar, Phys. Chem. Chem. Phys., 2008, 10, 2813. 